\title{
Multifractal analysis of human canine teeth at nano scale: atomic force microscopy studies
}

\author{
Shahram Solaymani ${ }^{1} \cdot$ Ştefan Ţălu ${ }^{2} \cdot$ Mahmood Ghoranneviss $^{1} \cdot$ Seyed Mohammad Elahi ${ }^{1}$ (10 . \\ Azizollah Shafiekhani $^{3,4} \cdot$ Mohammadreza Hantehzadeh $^{1} \cdot$ Negin Beryani Nezafat $^{1}$
}

Received: 23 October 2019 / Accepted: 22 December 2019 / Published online: 31 December 2019

(c) The Author(s) 2019

\begin{abstract}
The aim of the present study is to explore the 3-D micromorphology of human canine teeth materials using multifractal analysis through atomic force microscopy (AFM). The 3-D surfaces of ten extracted canine teeth of a group of 40 year old men were studied (enamel, inter enamel, inter dentin, and cementum) by AFM images in tapping mode and on square areas of $1 \mu \mathrm{m} \times 1 \mu \mathrm{m}(512 \times 512$ points $)$. The AFM images and surface multifractal analysis confirm the dependency of surface micromorphology to their structure-property of these materials across the length scales of the teeth structural architecture. Surface statistical parameters and hence, multifractal approach have been considered as reliable and sensitive tools for quantifying the 3-D surface microtexture changes of human canine teeth materials. The surface of inter dentin had the most irregular topography (the width spectrum $\Delta \alpha=2.8361$, value bigger than all the other $\Delta \alpha$ sample values), while the most regular topography (the width spectrum $\Delta \alpha=2.6804$, value lower than all the other sample values) was found in cementum. It has been concluded that multifractal analyses can be used as mathematical tools to explore the 3-D micromorphology of human canine teeth materials.
\end{abstract}

Keywords Atomic force microscopy (AFM) $\cdot 3$-D surface microtexture $\cdot$ Multifractal analysis $\cdot$ Human canine teeth materials

\section{Introduction}

The tooth represents one of the most interesting tissues in the human body, as to the performances in terms of material response [1]. This is also the case thanks to the stability of the adult teeth [2], which present a large mineralized portion in terms of their constituent materials and organization [3]. In this respect, the teeth are similar to bones, yet their

Seyed Mohammad Elahi

smohammad_elahi@srbiau.ac.ir

1 Department of Physics, Faculty of Sciences, Science and Research Branch, Islamic Azad University, Tehran, Iran

2 The Directorate of Research, Development and Innovation Management (DMCDI), Technical University of Cluj-Napoca, Constantin Daicoviciu St., No. 15, 400020 Cluj-Napoca, Cluj county, Romania

3 School of Physics, Institute for Research in Fundamental Sciences (IPM), Tehran, P.O. Box 19395-5531, Iran

4 Physics Department, Alzahra University, Tehran 1993891167, Iran degree of mineralization is higher, and, even if they are also live organs-which is especially clear when considering their interfaces at the periodontum ligament. The main teeth function is connected to the mechanical properties, mainly the elastic ones-stiffness and hardness [4]. This observation does not intend to minimize the effect of the biological interactions of the teeth with the body as well as with the environment. Nevertheless, for many applications still a simplified field of material-science may successfully apply to the investigation of their properties, which is also functional to the identification of appropriate substituting materials i.e., implants (metal/ceramics for the crowns and titanium alloy for the screws replacing the roots) and restorations (glassmonomer cements [gic] and resin composites) [5-7].

Several studies have already been carried out on the materials constituting the teeth, over the past decades, with the most disparate techniques, yet based mainly on a combination of microscopy and elastic characterization [8, 9]. Enamel, the universally recognized hardest and stiffest material in our body is composed of both organic and inorganic phase [10]. Dentin is obviously less stiff and plays a support 
role in buffering biting forces [2] that comprises a higher amount of organic phase [11]. For dentin, the situation is more difficult, since the material is a porous composite, and therefore a correct characterization should account for the porosity. The dentin microstructure consists of dentinal tubules that radiate outward through its volume, from the pulpal chamber to the exterior enamel or cementum [2]. Cementum is the last hard tissue of the tooth, which covers the surface in the sub-gingival region, with the compact structure like enamel (i.e., non-porous). However, it has the highest percentage of organic materials compared to the other regions [12].

On the other hand, different experimental and theoretical studies have reported the materials constituting human teeth, but there still remain many questions at basic levels about the structure-property relationship of these 3-D bio-structures across the length scales of the human teeth structural architecture [13-17].

Several recent nano-technological research lines emerge in dentistry that can provide new innovative ideas and concepts for solving pathological mechanisms and lead to novel therapeutic orientations [18-20]. In this context the 3-D shape models can be used to design, model, simulate, and visualize the teeth $3-\mathrm{D}$ geometry and to help in computeraided diagnosis [21-23].

Although the 3-D surface morphology of the human teeth is an extremely irregular and complex bio-structure with fine anatomic detail and surface texture, it can be analyzed quantitatively by applying the stereometric [24-26], fractal [27-29] or multifractal $[17,20]$ analyses of AFM micrograph samples.

The aim of this research was to examine the 3-D micromorphology of human canine teeth materials using AFM images and multifractal analysis.

\section{Experimental details}

Ten extracted permanent canine teeth of 40 year old men were collected for the experiment. Because of their similarity in their results, we represent the results of one of these specimens.

As the first step, all samples were placed in saline and brought to the laboratory. They were then brushed with standard dentifrice and tooth brush and kept in acetone and alcohol baths to remove their impurities ultrasonically. After drying them in air, all samples were cross-sectioned so that we were able to access to the inner parts.

AFM (Veeco, Santa Barbara, CA) images were applied to provide quantitative data about surface roughness and morphology for studying the structural topography of enamel, dentin, and cementum in the healthy tooth. The room temperature and ambient pressure was the same for all steps of experiments as $297 \pm 1 \mathrm{~K}$ and $50 \pm 1 \%$, respectively.

\section{Multifractal analysis of the 3-D surface micro-texture}

The analysis of surface topography with the fractal method attracts a lot of interest in the field of biomaterials surface [18-22] since it is considered as a useful tool for analysing irregular and complex structures of various types of biomaterials [26-28].

For a 3-D fractal surface, the statistical index $D$ is defined as fractal dimension with $2 \leq D \leq 3$ which extracts the complexity of structure [17]. It should be noted that higher $D$ values refer to the irregular surface with more complexity since it gives information about non-differentiability and self-similarity mathematically $[17,22]$.

However, when fractal analysis cannot describe surface topography due to its complexity, multifractal analysis is the most appropriate tool for characterization of surface morphology [30-34].

By considering $q$ as the order moment with real values from $-\infty$ (less dense areas) to $+\infty$ (dense areas), $D_{q}$ and $\alpha(q)$ represent information about fractal/multifractal geometry and are measured as the generalized dimension of Hölder exponents of $q$ while $f(\alpha)$ refer to singularity spectrum. Two multifractal parameters are related by the Legendre transformation [32-34].

The generalized fractal dimensions $D_{q}$ can be computed using the following formula [17]:

$D_{q}=\tau(q) /(q-1)$

where $\tau(q)$ is the mass (or correlation) exponent of the $q$ th order; and $q$ is the order moment.

The multifractal spectrum function can be expressed as [17]:

$f(\alpha(q))=q \alpha(q)-\tau(q)$

where $\alpha(q)=d \tau(q) / d q . \alpha_{q}$ represents Hölder exponents of the $q$ th order moment.

On the other hand, $D_{q}$ for $q=0,1,2$ is known as the capacity, information entropy, and correlation dimensions, respectively. The relation between these parameters is $D_{0}>D_{1}>D_{2}$. In addition, $\alpha_{\max }=D_{-\infty}$ and $\alpha_{\min }=D_{+\infty}$ for $q= \pm \infty$ with the width spectrum of $\Delta \alpha=\alpha_{\max }-\alpha_{\min }$, and heights difference of $\Delta f=f\left(\alpha_{\min }\right)-f\left(\alpha_{\max }\right)$ [32-34].

When $\Delta f<0$ and $\Delta f>0$, the fragments are explained by the low and high probability value predominate, respectively. The left arm (positive $q$ ) and right arm (negative $q$ ) of multifractal spectrum are related to irregular and flat areas, respectively [35]. By decreasing the value $D_{q}$ affected by increase of $q$, multifractal structure is created which 
demonstrated the dependency of $f(\alpha)$ to $\alpha$ and $D_{q}$ to $q$ by box counting method [17].

\section{Statistical analysis}

The GraphPad InStat version 3.20 computer software package (GraphPad, San Diego, CA, USA) was applied here to perform statistical investigations. Meanwhile, Kolmogorov-Smirnov test was applied to extract normal distributions. Moreover, $T$ test and Mann-Whitney $U$ test were used to compare various areas in typical sample and reveal statistical differences, respectively.

\section{Results and discussion}

Scanning electron microscopy (SEM) images shown in Fig. 1 reveal the presence of granular structures on different hard dental tissues. The sizes of these grains are about $70-150 \mathrm{~nm}$.

The representative 3-D AFM images for $1 \mu \mathrm{m} \times 1 \mu \mathrm{m}$ scanning square areas of hard dental tissue of the human canine teeth are shown in Fig. 2.
The functional dependences $R^{2}$-error versus $q$ are shown in Fig. 3. After small values of $R^{2}$-error in low values of $q$, it is rapidly raised. For $q>-1.2$, fractal properties exist for all samples.

Figure 4 shows multifractal analysis based on the boxcounting method which determines functional dependency of $f(\alpha)$ to $\alpha$ and $q$ to $D_{q}$ on each region of interest (ROI) (where $-20 \leq q \leq 20$ for successive 1.0 steps).

AFM images of each tissue exhibit multifractal nature of dental surface along with non-homogeneous nature.

For the surfaces of the human canine teeth, different fractal dimensions follows $D_{0}>D_{1}>D_{2}$ (Fig. 4a) which indicates the non-uniform features of 3-D surfaces. Figure $4 \mathrm{~b}$ illustrates the asymmetric non-linear curve of $f(q, r)-\alpha(q, r)$ with two arms and $\Delta \alpha$ width.

All the values of $\Delta \alpha>0$ and $\Delta f>0$ (Tables 1,2,3 and 4).

Compared to other tissue, longer right shoulder of $f(\alpha)$ along with the most irregular topography $(\Delta \alpha=2.8361)$ are illustrated in inter dentin. On the other hand, the most regular topography was observed in cementum $(\Delta \alpha=2.6804)$ (according Table 5).

A similar situation is observed for values of $\Delta f$ : the maximum value $\Delta f=0.7859$ is illustrated in inter dentin and the
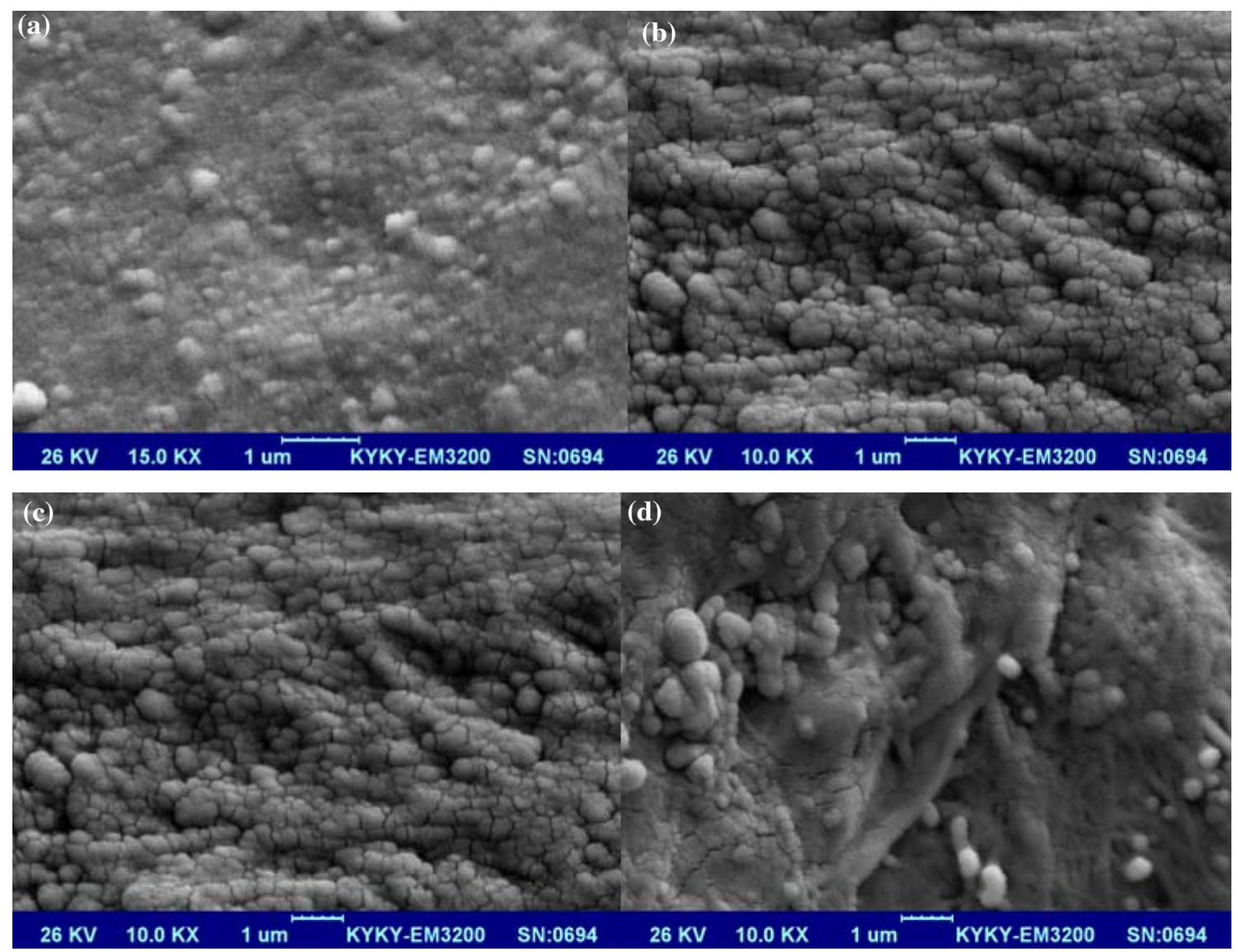

Fig. 1 SEM images of: $\mathbf{a}$ enamel, $\mathbf{b}$ inter enamel, $\mathbf{c}$ inter dentin, and $\mathbf{d}$ cementum 
Fig. 2 AFM micrographs of the human canine teeth materials: a enamel, $\mathbf{b}$ inter enamel, $\mathbf{c}$ inter dentin, and $\mathbf{d}$ cementum
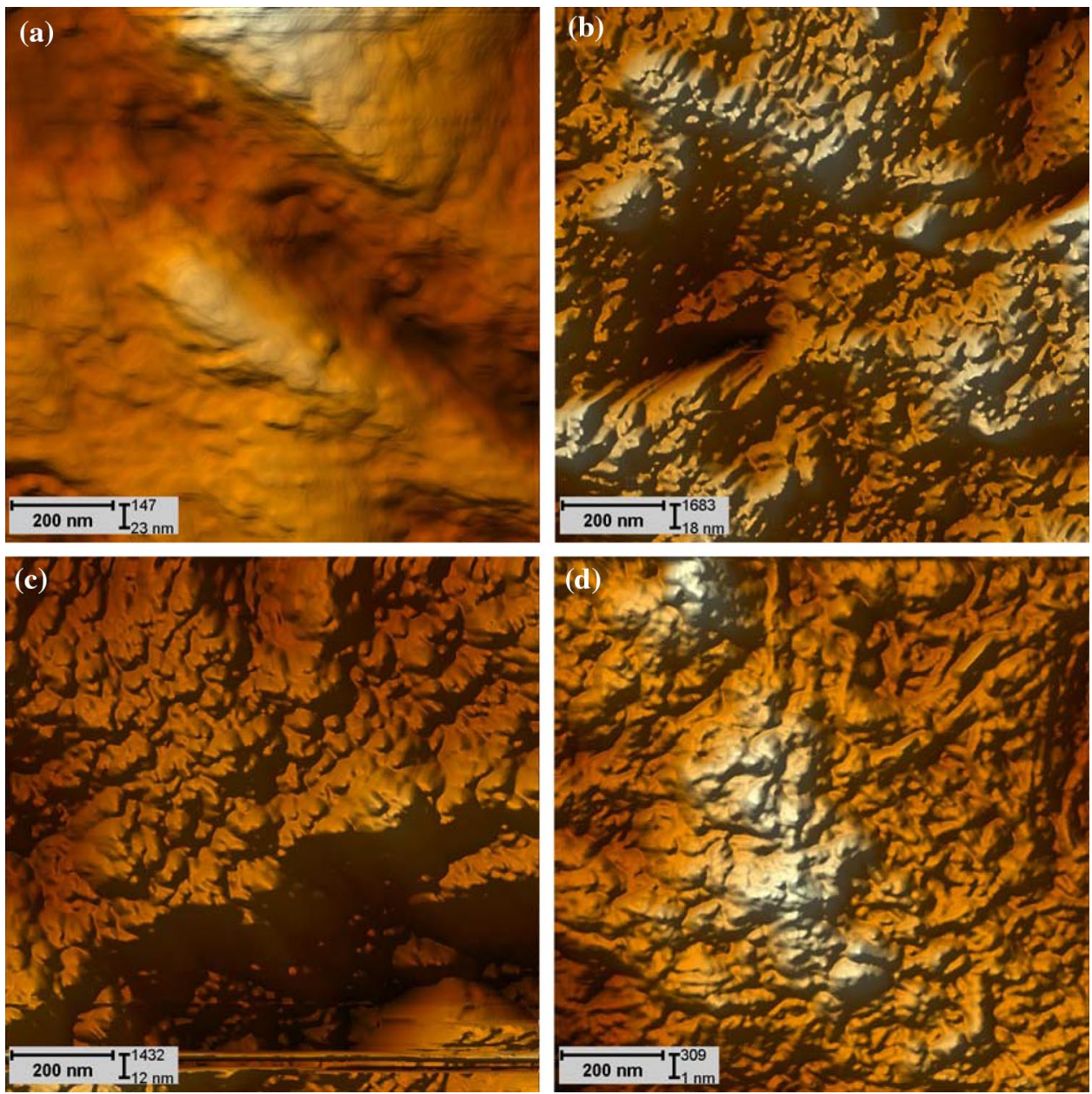

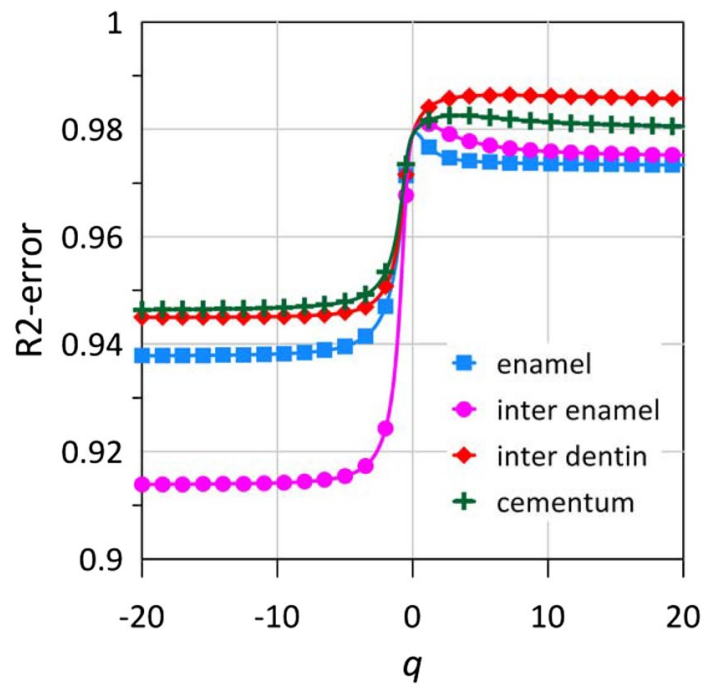

Fig. 3 The graphs of coefficient $R^{2}$-error versus $q$ for all dental tissue minimum value of $\Delta f=0.3028$ is observed in cementum (according Table 5).

Due to increasing surface roughness, the $f(q, r)-\alpha(q, r)$ curve deviation and hence, the inhomogeneity are increased. Larger values of $\Delta \alpha$ end to more differences between the lowest and highest probability along with wider probability distributions [35].

The $\Delta f=f\left(\alpha_{\min }\right)-f\left(\alpha_{\max }\right)$ is considered as the ratio of maximum-to-minimum probability. Here, the negative values of $\Delta f$ indicate the fragments explained by low probability value predominate. Moreover, significant correlation $(P<0.05)$ confirmed to accuracy of multifractal theory in estimating surface morphology which reveal non-uniform surfaces depend to human teeth materials. In addition, statistical parameters in Tables 1, 2, 3 and 4 are used to represent a powerful complement for 3-D surface morphology investigations more explicitly. 

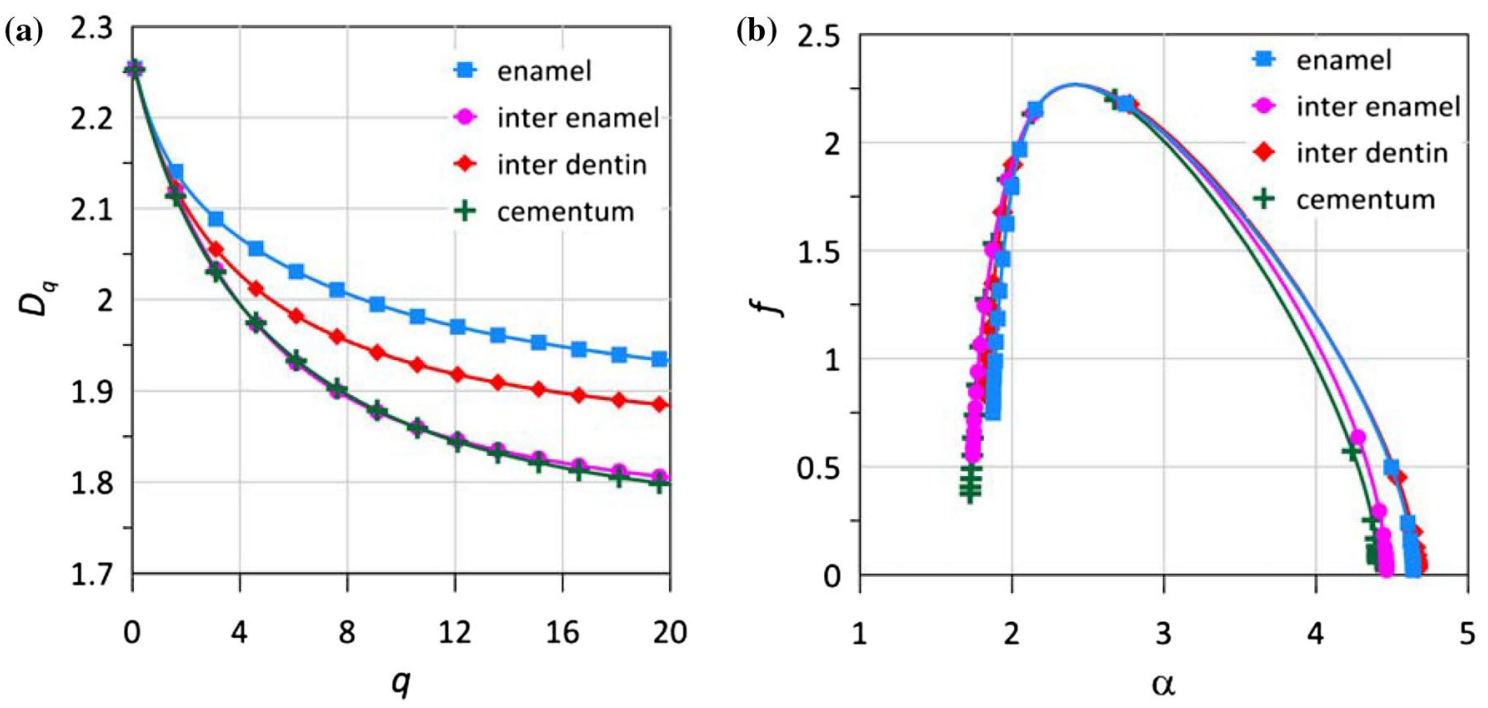

Fig. 4 Generalized $\mathbf{a}$ fractal and $\mathbf{b}$ multifractal spectrum for each tissue

Table 1 The values of $D_{q}$, $R^{2}$-error, $f(\alpha)$ for the surfaces of enamel on square areas of $1 \mu \mathrm{m} \times 1 \mu \mathrm{m}$

\begin{tabular}{llllllllll}
\hline$q$ & $D_{q}$ & $R^{2}$-error & $\alpha$ & $f(\alpha)$ & $q$ & $D_{q}$ & $R^{2}$-error & $\alpha$ & $f(\alpha)$ \\
\hline-20 & 4.4190 & 0.93785 & 4.6388 & 0.023686 & 0.1 & 2.2536 & 0.97930 & 2.3514 & 2.263420 \\
-19 & 4.4080 & 0.93786 & 4.6387 & 0.025532 & 1 & 2.1730 & 0.00584 & 2.1666 & 2.166626 \\
-18 & 4.3959 & 0.93788 & 4.6385 & 0.027667 & 2 & 2.1236 & 0.97519 & 2.0821 & 2.040774 \\
-17 & 4.3824 & 0.93789 & 4.6384 & 0.030154 & 3 & 2.0914 & 0.97442 & 2.0351 & 1.922521 \\
-16 & 4.3673 & 0.93791 & 4.6382 & 0.033068 & 4 & 2.0675 & 0.97408 & 2.0024 & 1.807126 \\
-15 & 4.3504 & 0.93793 & 4.6380 & 0.036505 & 5 & 2.0482 & 0.97389 & 1.9770 & 1.692316 \\
-14 & 4.3312 & 0.93796 & 4.6377 & 0.040582 & 6 & 2.0321 & 0.97377 & 1.9566 & 1.579417 \\
-13 & 4.3094 & 0.93799 & 4.6374 & 0.045449 & 7 & 2.0182 & 0.97369 & 1.9400 & 1.471104 \\
-12 & 4.2841 & 0.93804 & 4.6369 & 0.051296 & 8 & 2.0061 & 0.97363 & 1.9266 & 1.369818 \\
-11 & 4.2548 & 0.93810 & 4.6363 & 0.058371 & 9 & 1.9956 & 0.97358 & 1.9157 & 1.277087 \\
-10 & 4.2239 & 0.93817 & 4.6355 & 0.066059 & 10 & 1.9862 & 0.97353 & 1.9070 & 1.193479 \\
-9 & 4.1786 & 0.93828 & 4.6343 & 0.077650 & 11 & 1.9780 & 0.97349 & 1.8999 & 1.118830 \\
-8 & 4.1281 & 0.93844 & 4.6327 & 0.090960 & 12 & 1.9706 & 0.97346 & 1.8941 & 1.052532 \\
-7 & 4.0651 & 0.93866 & 4.6304 & 0.107923 & 13 & 1.9641 & 0.97343 & 1.8894 & 0.993763 \\
-6 & 3.9846 & 0.93901 & 4.6270 & 0.130168 & 14 & 1.9582 & 0.97341 & 1.8856 & 0.941643 \\
-5 & 3.8779 & 0.93958 & 4.6213 & 0.160736 & 15 & 1.9529 & 0.97339 & 1.8824 & 0.895322 \\
-4 & 3.7300 & 0.94057 & 4.6109 & 0.206564 & 16 & 1.9481 & 0.97337 & 1.8797 & 0.854026 \\
-3 & 3.5120 & 0.94252 & 4.5865 & 0.288599 & 17 & 1.9438 & 0.97335 & 1.8775 & 0.817072 \\
-2 & 3.1636 & 0.94696 & 4.4958 & 0.499443 & 18 & 1.9398 & 0.97333 & 1.8756 & 0.783869 \\
-1 & 2.5996 & 0.95914 & 3.7242 & 1.475003 & 19 & 1.9362 & 0.97332 & 1.8740 & 0.753911 \\
-0.1 & 2.2822 & 0.97841 & 2.4111 & 2.269390 & 20 & 1.9329 & 0.97330 & 1.8727 & 0.729369 \\
\hline & & & & & & & & &
\end{tabular}

\section{Conclusions}

The micromorphology of human canine teeth materials can be evaluated by multifractal analysis and revealed the multifractal geometry of samples at nanometer scale. The results represented here are new insights for the understanding of the structure-properties relationships (local composition, crystalline structure, local mechanical information) and to study of various physical phenomena at the nanoscale scale, for both experimental and theoretical perspectives.

These models provide a basis for further research and analysis with 3-D modern mathematical methods for the simulation of mechanical and physical phenomena at different length and time scales, such as fracture and cracks evolution of nanocrystalline human canine teeth materials for fatigue loading using computer graphics. 
Table 2 The values of $D_{q}$, $R^{2}$-error, $f(\alpha)$ for the surfaces of inter dentin on square areas of $1 \mu \mathrm{m} \times 1 \mu \mathrm{m}$

\begin{tabular}{llllllllll}
\hline$q$ & $D_{q}$ & $R^{2}$-error & $\alpha$ & $f(\alpha)$ & $q$ & $D_{q}$ & $R^{2}$-error & $\alpha$ & $f(\alpha)$ \\
\hline-20 & 4.4475 & 0.94493 & 4.6668 & 0.029603 & 0.1 & 2.2525 & 0.97982 & 2.3591 & 2.263200 \\
-19 & 4.4365 & 0.94493 & 4.6684 & 0.030973 & 1 & 2.1620 & 0.12049 & 2.1545 & 2.154500 \\
-18 & 4.4243 & 0.94494 & 4.6668 & 0.032499 & 2 & 2.1011 & 0.98521 & 2.0476 & 1.994000 \\
-17 & 4.4107 & 0.94495 & 4.6682 & 0.034196 & 3 & 2.0589 & 0.98586 & 1.9843 & 1.835100 \\
-16 & 4.3956 & 0.94496 & 4.6681 & 0.036120 & 4 & 2.0274 & 0.98616 & 1.9431 & 1.690300 \\
-15 & 4.3786 & 0.94497 & 4.6679 & 0.038319 & 5 & 2.0002 & 0.98630 & 1.9149 & 1.562800 \\
-14 & 4.3593 & 0.94498 & 4.6677 & 0.040860 & 6 & 1.9834 & 0.98635 & 1.8949 & 1.452100 \\
-13 & 4.3373 & 0.94500 & 4.6675 & 0.043839 & 7 & 1.9675 & 0.98635 & 1.8803 & 1.356800 \\
-12 & 4.3119 & 0.94503 & 4.6672 & 0.047380 & 8 & 1.9543 & 0.98632 & 1.8694 & 1.275000 \\
-11 & 4.2823 & 0.94506 & 4.6669 & 0.051662 & 9 & 1.9432 & 0.98627 & 1.8611 & 1.204600 \\
-10 & 4.2473 & 0.94510 & 4.6663 & 0.056942 & 10 & 1.9338 & 0.98621 & 1.8548 & 1.143900 \\
-9 & 4.2054 & 0.94515 & 4.6656 & 0.063605 & 11 & 1.9256 & 0.98615 & 1.8498 & 1.091300 \\
-8 & 4.1544 & 0.94523 & 4.6646 & 0.072266 & 12 & 1.9186 & 0.98608 & 1.8458 & 1.045400 \\
-7 & 4.0907 & 0.94535 & 4.6630 & 0.083963 & 13 & 1.9124 & 0.98602 & 1.8624 & 1.004900 \\
-6 & 4.0090 & 0.94553 & 4.6604 & 0.100570 & 14 & 1.9069 & 0.98596 & 1.8399 & 0.968980 \\
-5 & 3.9008 & 0.94584 & 4.6558 & 0.125700 & 15 & 1.9021 & 0.98591 & 1.8377 & 0.936800 \\
-4 & 3.7505 & 0.94642 & 4.6464 & 0.167030 & 16 & 1.8977 & 0.98586 & 1.8358 & 0.907730 \\
-3 & 3.5287 & 0.94765 & 4.6232 & 0.245030 & 17 & 1.8938 & 0.98581 & 1.8342 & 0.881250 \\
-2 & 3.1732 & 0.95077 & 4.5347 & 0.450310 & 18 & 1.8902 & 0.98576 & 1.8328 & 0.856940 \\
-1 & 2.6034 & 0.96051 & 3.6909 & 1.515900 & 19 & 1.8870 & 0.98572 & 1.8316 & 0.834460 \\
-0.1 & 2.2835 & 0.97805 & 2.4230 & 2.269500 & 20 & 1.8841 & 0.98569 & 1.8307 & 0.815560 \\
\hline & & & & & & & &
\end{tabular}

Table 3 The values of $D_{q}$, $R^{2}$-error, $f(\alpha)$ for the surfaces of inter enamel on square areas of $1 \mu \mathrm{m} \times 1 \mu \mathrm{m}$

\begin{tabular}{llllllllll}
\hline$q$ & $D_{q}$ & $R^{2}$-error & $\alpha$ & $f(\alpha)$ & $q$ & $D_{q}$ & $R^{2}$-error & $\alpha$ & $f(\alpha)$ \\
\hline-20 & 4.2530 & 0.91390 & 4.4646 & 0.021436 & 0.1 & 2.2530 & 0.97964 & 2.3574 & 2.263400 \\
-19 & 4.2424 & 0.91391 & 4.4645 & 0.023228 & 1 & 2.1609 & 0.13939 & 2.1528 & 2.152800 \\
-18 & 4.2307 & 0.91392 & 4.4643 & 0.025327 & 2 & 2.0918 & 0.97999 & 2.0266 & 1.961300 \\
-17 & 4.2177 & 0.91393 & 4.4642 & 0.027806 & 3 & 2.0381 & 0.97879 & 1.9383 & 1.738600 \\
-16 & 4.2032 & 0.91394 & 4.4640 & 0.030754 & 4 & 1.9550 & 0.97790 & 1.8769 & 1.522700 \\
-15 & 4.1870 & 0.91396 & 4.4638 & 0.034285 & 5 & 1.9605 & 0.97727 & 1.8360 & 1.338200 \\
-14 & 4.1685 & 0.91398 & 4.4635 & 0.038541 & 6 & 1.9330 & 0.97681 & 1.8093 & 1.190700 \\
-13 & 4.1474 & 0.91401 & 4.4631 & 0.043706 & 7 & 1.9110 & 0.97647 & 1.7916 & 1.075200 \\
-12 & 4.1232 & 0.91405 & 4.4626 & 0.050017 & 8 & 1.8931 & 0.97621 & 1.7795 & 0.984290 \\
-11 & 4.0949 & 0.91410 & 4.4619 & 0.057790 & 9 & 1.8784 & 0.97600 & 1.7709 & 0.911140 \\
-10 & 4.0616 & 0.91416 & 4.4610 & 0.067457 & 10 & 1.8661 & 0.97584 & 1.7646 & 0.850800 \\
-9 & 4.0217 & 0.91426 & 4.4597 & 0.079632 & 11 & 1.8557 & 0.97571 & 1.7597 & 0.799770 \\
-8 & 3.9731 & 0.91439 & 4.4579 & 0.095243 & 12 & 1.8468 & 0.97560 & 1.7559 & 0.755680 \\
-7 & 3.9127 & 0.91459 & 4.4551 & 0.115790 & 13 & 1.8391 & 0.97550 & 1.7528 & 0.716910 \\
-6 & 3.8354 & 0.91492 & 4.4507 & 0.143860 & 14 & 1.8324 & 0.97543 & 1.7502 & 0.682380 \\
-5 & 3.7334 & 0.91547 & 4.4432 & 0.184420 & 15 & 1.8264 & 0.97536 & 1.7481 & 0.651310 \\
-4 & 3.5926 & 0.91648 & 4.4287 & 0.248050 & 16 & 1.8212 & 0.97530 & 1.7463 & 0.623160 \\
-3 & 3.3867 & 0.91865 & 4.3947 & 0.362590 & 17 & 1.8164 & 0.97525 & 1.7447 & 0.597490 \\
-2 & 3.0637 & 0.92435 & 4.2765 & 0.637960 & 18 & 1.8122 & 0.97521 & 1.7434 & 0.573990 \\
-1 & 2.5708 & 0.94507 & 3.5079 & 1.633600 & 19 & 1.8083 & 0.97517 & 1.7422 & 0.552400 \\
-0.1 & 2.2827 & 0.97809 & 2.4166 & 2.269300 & 20 & 1.8048 & 0.97514 & 1.7413 & 0.534430 \\
\hline & & & & & & & & &
\end{tabular}


Table 4 The values of $D_{q}$, $R^{2}$-error, $f(\alpha)$ for the surfaces of cementum on square areas of $1 \mu \mathrm{m} \times 1 \mu \mathrm{m}$

\begin{tabular}{llllllllll}
\hline$q$ & $D_{q}$ & $R^{2}$-error & $\alpha$ & $f(\alpha)$ & $q$ & $D_{q}$ & $R^{2}$-error & $\alpha$ & $f(\alpha)$ \\
\hline-20 & 4.1992 & 0.94635 & 4.4061 & 0.060802 & 0.1 & 2.2534 & 0.97944 & 2.3560 & 2.263700 \\
-19 & 4.1889 & 0.94637 & 4.4060 & 0.062811 & 1 & 2.1598 & 0.00030 & 2.1513 & 2.151300 \\
-18 & 4.1774 & 0.94639 & 4.4059 & 0.064974 & 2 & 2.0882 & 0.98228 & 2.0224 & 1.956500 \\
-17 & 4.1647 & 0.94641 & 4.4058 & 0.067320 & 3 & 2.0353 & 0.98254 & 1.9398 & 1.748800 \\
-16 & 4.1506 & 0.94643 & 4.4056 & 0.069880 & 4 & 1.9945 & 0.98250 & 1.8840 & 1.522400 \\
-15 & 4.1346 & 0.94646 & 4.4054 & 0.072701 & 5 & 1.9622 & 0.98232 & 1.8444 & 1.373300 \\
-14 & 4.1166 & 0.94649 & 4.4052 & 0.075840 & 6 & 1.9359 & 0.98210 & 1.8152 & 1.211900 \\
-13 & 4.0960 & 0.94653 & 4.4049 & 0.079383 & 7 & 1.9140 & 0.98188 & 1.7933 & 1.068900 \\
-12 & 4.0722 & 0.94658 & 4.4046 & 0.083447 & 8 & 1.8956 & 0.98167 & 1.7767 & 0.944300 \\
-11 & 4.0445 & 0.94664 & 4.4042 & 0.088208 & 9 & 1.8800 & 0.98148 & 1.7642 & 0.837830 \\
-10 & 4.0119 & 0.94672 & 4.4036 & 0.093932 & 10 & 1.8667 & 0.98132 & 1.7548 & 0.748100 \\
-9 & 3.9727 & 0.94682 & 4.4029 & 0.101040 & 11 & 1.8552 & 0.98118 & 1.7477 & 0.673170 \\
-8 & 3.9250 & 0.94695 & 4.4018 & 0.110210 & 12 & 1.8452 & 0.98106 & 1.7423 & 0.610830 \\
-7 & 3.8654 & 0.94714 & 4.4001 & 0.122640 & 13 & 1.8364 & 0.98096 & 1.7382 & 0.558950 \\
-6 & 3.7892 & 0.94741 & 4.3973 & 0.140520 & 14 & 1.8288 & 0.98087 & 1.7350 & 0.515600 \\
-5 & 3.6882 & 0.94784 & 4.3922 & 0.168240 & 15 & 1.8220 & 0.98079 & 1.7324 & 0.479150 \\
-4 & 3.5482 & 0.94857 & 4.3814 & 0.215760 & 16 & 1.8159 & 0.98073 & 1.7305 & 0.448280 \\
-3 & 3.3425 & 0.95000 & 4.3530 & 0.311010 & 17 & 1.8105 & 0.98067 & 1.7289 & 0.421900 \\
-2 & 3.0177 & 0.95340 & 4.2395 & 0.574250 & 18 & 1.8057 & 0.98062 & 1.7276 & 0.399160 \\
-1 & 2.5337 & 0.96337 & 3.3763 & 1.691100 & 19 & 1.8013 & 0.98058 & 1.7265 & 0.379380 \\
-0.1 & 2.2820 & 0.97846 & 2.4107 & 2.269200 & 20 & 1.7974 & 0.98054 & 1.7257 & 0.363670 \\
\hline & & & & & & & & &
\end{tabular}

Table 5 The multifractal width spectrum, $\Delta \alpha=\alpha_{\max }-\alpha_{\min }$ and the spectrum arms' height $\Delta f=f\left(\alpha_{\min }\right)-f\left(\alpha_{\max }\right)$

\begin{tabular}{lllll}
\hline The multifractal width spectrum & Enamel & Inter dentin & Inter enamel & Root \\
\hline$\Delta \alpha=\alpha_{\text {max }}-\alpha_{\text {min }}$ & $\Delta \alpha=2.7661$ & $\Delta \alpha=2.8361$ & $\Delta \alpha=2.7233$ & $\Delta \alpha=2.6804$ \\
$\Delta f=f\left(\alpha_{\text {min }}\right)-f\left(\alpha_{\text {max }}\right)$ & $\Delta f=0.7056$ & $\Delta f=0.7859$ & $\Delta f=0.5129$ & $\Delta f=0.3028$ \\
\hline
\end{tabular}

Statistically significant difference for all values: $P<0.05$

\section{Compliance with ethical standards}

Conflict of interest The authors report no conflict of interests. The authors alone are responsible for the content and writing of the paper.

Open Access This article is licensed under a Creative Commons Attribution 4.0 International License, which permits use, sharing, adaptation, distribution and reproduction in any medium or format, as long as you give appropriate credit to the original author(s) and the source, provide a link to the Creative Commons licence, and indicate if changes were made. The images or other third party material in this article are included in the article's Creative Commons licence, unless indicated otherwise in a credit line to the material. If material is not included in the article's Creative Commons licence and your intended use is not permitted by statutory regulation or exceeds the permitted use, you will need to obtain permission directly from the copyright holder. To view a copy of this licence, visit http://creativecommons.org/licenses/by/4.0/.

\section{Appendix}

The values of $f(\alpha)$ for all tissues are listed in Tables 1,2, 3 and 4 .

\section{References}

1. Nezafat, N.B., Ghoranneviss, M., Elahi, S.M., Shafiekhani, A., Ghorannevis, Z., Solaymani, S.: Microstructure, micromorphology, and fractal geometry of hard dental tissues: evaluation of atomic force microscopy images. Microsc. Res. Tech. 82, 1884 1890 (2019)

2. Driessens, F.C.M.: The mineral in bone, dentin and tooth enamel. Bull. Soc. Chim. Belg. 89, 8 (1980)

3. Sehroeder, L., Frank, R.M.: High-resolution transmission electron microscopy of adult human peritubular dentine. Cell Tissue Res. 242, 449-451 (1985)

4. Rey, C., Renugopalakrishnan, V., Shimizu, M., Collins, B., Giimcher, M.J.: A resolution-enhanced fourier transform infrared spectroscopic study of the environment of the $\mathrm{CO}_{3}(2-)$ ion in the mineral phase of enamel during its formation and maturation. Calcif. Tissue Int. 49, 259-268 (1991)

5. Arora, M., Chan, S.W.Y., Kennedy, B.J., Sharma, A., Crisante, D., Walker, D.M.: Spatial distribution of lead in the roots of human primary teeth. J. Trace Elem. Med Biol. 18, 135-139 (2004)

6. Feilzer, A.J., De, A.J., Davidson, C.L.: Curing contraction of composites and glass-ionomer cements. J. Prosthet. Dent. 59, 3-297 (1988)

7. Barfeie, A., Wilson, J., Rees, J.: Implant surface characteristics and their effect on osseointegration. Br. Dent. J. 218, 9 (2015) 
8. Povolo, F., Hermida, E.B.: Measurement of the elastic modulus of dental pieces. J. Alloy. Compd. 310, 392-395 (2000)

9. Zhang, Y., Arsecularatne, J.A., Hoffman, M.: The effects of three different food acids on the attrition-corrosion wear of human dental enamel. J. Phys. D Appl. Phys. 48, 285401 (2015)

10. Pramanik, A., Zhang, L.C., Arsecularatne, J.A.: Machining of metal matrix composites: effect of ceramic particles on residual stress, surface roughness and chip formation. Int. J. Mach. Tool. Manuf. 48, 1613-1625 (2008)

11. Carlén, A., Börjesson, A.C., Nikdel, K., Olsson, J.: Composition of pellicles formed in vivo on tooth surfaces in different parts of the dentition, and in vitro on hydroxyapatite. Caries Res. 32, 447-455 (1998)

12. Ghose, A.K., Viswanadhan, V.N., Wendoloski, J.J.: A knowledgebased approach in designing combinatorial or medicinal chemistry libraries for drug discovery. 1 . A qualitative and quantitative characterization of known drug databases. J. Comb. Chem 1, 55-68 (1999)

13. Selvig, K.A.: Periodic lattice images of hydroxyapatite crystals in human bone and dental hard tissues. Calc. Tiss. Res. 6, 227-238 (1970)

14. Cao, ChY, Mei, M.L., Li, Q., Lo, EChM, Chu, ChH: Methods for biomimetic mineralisation of human enamel: a systematic review. Materials 8, 2873-2886 (2015)

15. Kirchner, M.T., Edwards, H.G.M., Lucy, D., Pollard, A.M.: Ancient and modern specimens of human teeth: a transform spectroscopic study. J. Raman Spectrosc. 28, 171-178 (1997)

16. Salerno, M., Diaspro, A.: Dentistry on the bridge to nanoscience and nanotechnology. Front. Mater. 2, 1-10 (2015)

17. Ţălu, Ş.: Micro and nanoscale characterization of three dimensional surfaces: basics applications. Napoca Star Publishing House, Cluj-Napoca (2015)

18. González-Nilo, F., Pérez-Acle, T., Guínez-Molinos, S., Geraldo, D.A., Sandoval, C., Yévenes, A., Santos, L.S., Felipe, Laurie V., Mendoza, H., Cachau, R.E.: Nanoinformatics: an emerging area of information technology at the intersection of bioinformatics, computational chemistry and nanobiotechnology. Biol. Res. 44, 43-51 (2011)

19. Morozov, I.A., Svistkov, A.L., Gileva, O.S., Erofeeva, E.S.: Experimental investigation of the influence of bleaching on enamel surface microstructure. Russ. J. Biomech. 14(1), 56-63 (2010)

20. Morozov, I.A., Belyaev, A.Y., Izyumov, R.I., Erofeeva, E.S., Gileva, O.S.: Impact of whitening on the microstructure of human tooth enamel. Inorg. Mater. Appl. Res. 4(1), 71-76 (2013)

21. Ţălu, S..: Texture analysis methods for the characterisation of biological and medical images. Extreme Life Biospeol. Astrobiol. 4, 8-12 (2012)

22. Dejam, L., Solaymani, S., Achour, A., Stach, S., Ţălu, Ş., Nezafat, N.B., Dalouji, V., Shokri, A., Ghaderi, A.: Correlation between surface topography, optical band gaps and crystalline properties of engineered AZO and CAZO thin films. Chin. Phys. Lett. 719, 78-90 (2019)

23. Mahmoodi, A., Solaymani, S., Amini, M., Nezafat, N.B., Ghoranneviss, M.: Structural, morphological and antibacterial characterization of CuO nanowires. Silicon 10(4), 1427-1431 (2018)
24. Zare, M., Solaymani, S., Shafiekhani, A., Kulesza, S., Ţălu, Ş., Bramowicz, M.: Evolution of rough-surface geometry and crystalline structures of aligned $\mathrm{TiO}_{2}$ nanotubes for photoelectrochemical water splitting. Sci. Rep. 8(1), 10870 (2018)

25. Grmela, L., Sobola, D., Ţălu, S.., Solaymani, S.: Influence of scanning rate on quality of AFM image: study of surface statistical metrics. Microsc. Res. Tech. 80(11), 1328-1336 (2017)

26. Solaymani, S., Kulesza, S., Ţălu, Ş., Bramowicz, M., Nezafat, N.B., Dalouji, V., Rezaee, S., Karami, H., Malekzadeh, M., Dorbidi, E.S.: The effect of different laser irradiation on rugometric and microtopographic features in zirconia ceramics: study of surface statistical metrics. J. Alloy. Compd. 765, 180-185 (2018)

27. Ţălu, Ş., Yadav, R.P., Lainovic, T., Méndez-Albores, A., Trejo, G., Kukuruzovic, D., Nezafat, N.B., Shafiekhani, A., Solaymani, S.: The effect of dental LED light-curing unit photoactivation mode on 3D surface morphology of dental nanocomposites evaluated by two-dimensional multifractal detrended fluctuation analysis. Microsc. Res. Tech. 81(10), 1223-1230 (2018)

28. Solaymani, S., Ghoranneviss, M., Elahi, S.M., Shafiekhani, A., Kulesza, S., Ţălu, Ş., Bramowicz, M., Hantehzadeh, M., Nezafat, N.B.: The relation between structural, rugometric and fractal characteristics of hard dental tissues at micro and nano levels. Microsc. Res. Tech. 82(4), 421-428 (2018)

29. Hara, A.T., Livengood, S.V., Lippert, F., Eckert, G.J., Ungar, P.S.: Dental surface texture characterization based on erosive tooth wear processes. J. Dent. Res. 95(5), 537-542 (2016)

30. Dalouji, V., Solaymani, S., Dejam, L., Elahi, S.M., Rezaee, S., Mehrparvar, D.: Gap states of $\mathrm{ZnO}$ thin films by new methods: optical spectroscopy, optical conductivity and optical dispersion energy. Chin. Phys. Lett. 35(2), 027701 (2018)

31. Dalouji, V., Elahi, S.M., Ghaderi, A., Solaymani, S.: Porosity evaluation and the power spectral densities analyses of carbonnickel composite films annealed at different temperatures. Chin. Phys. Lett. 33(8), 086601 (2016)

32. Ţălu, Ş., Stach, S.: Multifractal characterization of unworn hydrogel contact lens surfaces. Polym. Eng. Sci. 54(5), 1066-1080 (2014)

33. Țălu, Ş., Marković, Z., Stach, S., Marković, B.T., Ţălu, M.: Multifractal characterization of single wall carbon nanotube thin films surface upon exposure to optical parametric oscillator laser irradiation. Appl. Surf. Sci. 289, 97-106 (2014)

34. Ţălu, Ş., Stach, S., Valedbagi, S., Bavadi, R., Elahi, S.M., Ţălu, M.: Multifractal characteristics of titanium nitride thin films. Mater. Sci. Poland. 33(3), 541-548 (2015)

35. Kwaśny, W.: Predicting properties of PVD and CVD coatings based on fractal quantities describing their surface. J. Achiev. Mater. Manuf. Eng. 2(37), 125-192 (2009)

Publisher's Note Springer Nature remains neutral with regard to jurisdictional claims in published maps and institutional affiliations. 